\title{
Transcriptomic responses of the liver and adipose tissues to altered carbohydrate-fat ratio in diet: an isoenergetic study in young rats
}

Mitsuru Tanaka ${ }^{1}$, Akihito Yasuoka², Manae Shimizu ${ }^{3}$, Yoshikazu Saito ${ }^{4}$, Kei Kumakura ${ }^{3}$, Tomiko Asakura ${ }^{4}$ and Toshitada Nagai ${ }^{3^{*}}$

\begin{abstract}
Background: To elucidate the effects of altered dietary carbohydrate and fat balance on liver and adipose tissue transcriptomes, 3-week-old rats were fed three kinds of diets: low-, moderate-, and high-fat diets $(L, M$, and $H)$ containing a different ratio of carbohydrate-fat (C-F) (65:15, 60:20, and 35:45 in energy percent, respectively).

Methods: The rats consumed the diets for 9 weeks and were subjected to biochemical and DNA microarray analyses.

Results: The rats in the H-group exhibited lower serum triacylglycerol (TG) levels but higher liver TG and cholesterol content than rats in the L-group. The analysis of differentially expressed genes (DEGs) between each group ( $L$ vs $M, M$ vs $H$, and $L$ vs $H$ ) in the liver revealed about $35 \%$ of $L$ vs $H$ DEGs that were regulated in the same way as $M$ vs $H$ DEGs, and most of the others were L- vs H-specific. Gene ontology analysis of these L vs H DEGs indicated that those related to fatty acid synthesis and circadian rhythm were enriched. Interestingly, about 30\% of L vs M DEGs were regulated in a reverse way compared with L vs H and M vs H DEGs. These reversed liver DEGs included M-up/H-down genes (Sds for gluconeogenesis from amino acids) and M-down/H-up genes (Gpd2 for gluconeogenesis from glycerol, Agpat9 for TG synthesis, and Acot1 for beta-oxidation). We also analyzed L vs H DEGs in white (WAT) and brown (BAT) adipose tissues and found that both oxidation and synthesis of fatty acids were inhibited in these tissues.
\end{abstract}

Conclusions: These results indicate that the alteration of dietary C-F balance differentially affects the transcriptomes of metabolizing and energy-storing tissues.

Keywords: Transcriptome, Carbohydrate-fat ratio, Liver, White adipose tissue, Brown adipose tissue

\section{Background}

Availability of body carbohydrate (C) and fat (F) for energy production varies depending on the animal's circumstances. Fat is mainly consumed during resting conditions at about $90 \%$ of total energy; however, this ratio can be rapidly decreased to nearly $10 \%$ through acute bouts of exercise and substituted by the energy supply from aerobic or anaerobic respiration of $C[7,38]$. Under fasting conditions, carbohydrate is depleted within a day, and about four fifths of basal metabolic rate is

\footnotetext{
* Correspondence: tnagai@takasaki-u.ac.jp

${ }^{3}$ Department of Health and Nutrition, Takasaki University of Health and

Welfare, 37-1 Nakaorui-machi, Takasaki, Gunma 370-0033, Japan

Full list of author information is available at the end of the article
}

maintained by fat and the rest by amino acids for several days [4]. These metabolic switches of energy source between $\mathrm{C}$ and $\mathrm{F}$ are more interchangeable than protein $(\mathrm{P})$ or amino acids because of the metabolic linkage mediated by the key organic substances: glycerol-3phosphate both as the product of triacylglycerol (TG) hydrolysis and as the substrate for gluconeogenesis, $\operatorname{NADP}(\mathrm{H})$ both as the hydrogen acceptor of the pentose phosphate pathway and as the hydrogen donor for fatty acid (FA) synthesis, and acetyl-CoA as the activated substrate of the TCA cycle and of FA synthesis. Thus, dietary $\mathrm{C}$ to $\mathrm{F}$ ratio (C-F ratio) has a considerable effect on the energy homeostasis of animals. 
Generally, experimental rodents accept diets composed of energetic C-F ranging from 50:30 to 70:10 to provide a constant energy ratio of $20 \% \mathrm{P}$ [39]. In rodents, AIN93G $(\mathrm{C}: \mathrm{F}: \mathrm{P}=64: 16: 20)$ during rapid growth, pregnancy, and lactation and AIN93M (C:F:P = 76:9:15) during maintenance were often used for standard diets [28]. Keeping this $\mathrm{P}$ energy ratio over $15 \%$ is critical for normal growth of adolescent animals [13, 23, 29]. But effects of an altered $\mathrm{C}-\mathrm{F}$ on metabolic parameters differ depending on dietary fat species such as soybean and corn oils of plant origin, and beef tallow and lard of animal origin. It was shown that a high-fat diet (HFD, C:F:P = 30:40:20) made of lard was more deleterious to insulin resistance and hepatic steatosis than an HFD made of soybean oil in comparison with a low-fat diet (LFD, C:F:P = 14:64:22) [45, 50]. Deol et al. reported that an HFD (C:F:P = 43:40:16) containing soybean oil and hydrogenated coconut oil at 1:1 ratio was more obesogenic than an HFD mainly containing hydrogenated coconut oil [10]. These differences were considered to be caused by the lipid composition of the dietary fat $[1,8,12,17,32,34]$. Polyunsaturated FAs (PUFAs) are the main contributors to the physiological activity of dietary fat; soybean oil contains 15\% saturated FAs and 55\% PUFAs, while lard contains $40 \%$ saturated FAs and $10 \%$ PUFAs. Duivenvoorde et al. showed that an HFD with predominantly saturated FAs increased ectopic fat storage, liver damage, and adipocyte size as compared to an HFD with predominantly PUFAs and reduced response flexibility to fast re-feeding and oxygen restriction [11]. Especially, eicosapentaenoic (EPA) and docosahexaenoic acid (DHA) were reported to reduce insulin resistance and hepatic steatosis $[26,31]$. Though small in percentage, sterols are critical factors for animal lipid homeostasis; the soybean oil used in our study contained $0.0024 \%$ cholesterol and $0.33 \%$ phytosterols, while the lard contained $0.086 \%$ cholesterol and no phytosterols. Specifically, phytosterols have been shown to exert beneficial effects on lipid homeostasis under metabolically stressed conditions such as an HFD containing predominantly saturated FAs $[5,6,16,27,36]$. However, there are few studies on the transcriptomic effects of a gradual change in the C-F under more moderate conditions, such as the use of diets containing natural plant oils or restricted feeding [30, 37]. In the present study, we conducted an isoenergetic study using a soybean oil-rich diet and found fewer deleterious effects on tissue metabolism but a drastic change in the tissue transcriptome.

\section{Methods}

\section{Animals}

Three-week-old male Wistar rats (Charles River Laboratories Japan, Kanagawa, Japan) were housed in a temperature- and humidity-controlled room with a 12-h light-dark cycle (light 06:30-18:30, dark 18:30-06:30).
All animal experimental protocols were approved by the Animal Use Committee of the Takasaki University of Health and Welfare.

\section{Experimental procedure}

The rats were acclimated to the laboratory environment for a week with chow diets (MF, Oriental yeast, Tokyo, Japan). The animals were divided into three groups so that the average body weights of each group were equal to each other before being given diets with different C-F energy ratios: low (L) 65:15, moderate (M) 60:20, and high $(\mathrm{H})$ 35:45 fat diet groups. The rats were fed diets ad libitum for a week. Then, the L-group was fed ad libitum and the other groups were fed isoenergetically compared with the L-group for 9 weeks. The diets were purchased from Research Diets, Inc. (New Brunswick, NJ, USA). Detailed compositions of each diet are shown in Additional file 1. Diets were removed $17 \mathrm{~h}$ before dissection, and the rats were sacrificed to collect the blood, liver, white adipose tissue (WAT), and brown adipose tissue (BAT). Because an obviously decreased dietary intake was observed for two rats belonging to the $\mathrm{M}$ - or $\mathrm{H}$-groups (M_7 and $\mathrm{H} \_11$ in identical number), the use of these two rats were not included in all analyses to achieve consistency in the isoenergetic study ( $n=4-5$ in each group). Serum and plasma were extracted using standard methods and separated from whole blood. Small hepatic pieces were immersed into RNAlater (Qiagen, Tokyo, Japan). The rest hepatic pieces, WAT, and BAT were frozen immediately after extirpation using liquid nitrogen. All samples were stored at -80 or $-150{ }^{\circ} \mathrm{C}$ until analysis.

\section{Measurement of blood biochemical parameters}

All blood biochemical parameters, except insulin, listed in Table 1, were analyzed by Nagahama Life Science (Shiga, Japan). Plasma was used to measure glucose, pyruvic acid, total lipids, phospholipids, and total ketone bodies. Other parameters were assayed using the serum. Serum insulin levels were measured by using the rat insulin ELISA kit (Morinaga Institute of Biological Science, Kanagawa, Japan).

\section{Measurement of hepatic lipids}

Hepatic lipids were extracted according to a previous method [14]. Briefly, $100 \mathrm{mg}$ of frozen hepatic pieces were homogenized in $2 \mathrm{~mL}$ of cooled chloroformmethanol solution (2:1) using a multibead shocker (Yasui Kikai Corporation, Osaka, Japan). Filtered samples were adjusted to $4 \mathrm{~mL}$ with chloroform-methanol solution and were washed with $0.8 \mathrm{~mL}$ of purified water. Subsequent washes were performed by adding $3.75 \mathrm{~mL}$ of chloroform-methanol-water solution (2:1:0.75), and the resulting extracts were dried by evaporation. Extracted lipids were resolved with $1 \mathrm{~mL}$ of isopropanol. 
Table 1 Blood and liver biochemical analysis

\begin{tabular}{llccc}
\hline & L-group & M-group & H-group \\
\hline Aspartate Aminotransferase (IU / L) & $128 \pm 16$ & $126 \pm 5$ & $154 \pm 22$ \\
Alanine Aminotransferase (IU / L) & $25 \pm 2^{\mathrm{a}}$ & $23 \pm 4^{\mathrm{a}}$ & $52 \pm 13^{\mathrm{b}}$ \\
Alkaline Phosphatase (IU / L) & $232 \pm 43$ & $194 \pm 52$ & $247 \pm 39$ \\
Lactate Dehydrogenase (IU / L) & $2136 \pm 375$ & $2183 \pm 310$ & $1866 \pm 228$ \\
Leucine Aminopeptidase (IU / L) & $71 \pm 4$ & $71 \pm 5$ & $79 \pm 5$ \\
Choline Esterase (IU / L) & $13 \pm 2$ & $13 \pm 2$ & $14 \pm 3$ \\
Total Bilirubin (mg / dL) & $0.07 \pm 0.02$ & $0.07 \pm 0.01$ & $0.07 \pm 0.02$ \\
Glucose (mg / dL) & $154 \pm 17$ & $160 \pm 20$ & $160 \pm 14$ \\
Pyruvic Acid (mg / dL) & $2.37 \pm 1.07$ & $1.68 \pm 1.50$ & $2.45 \pm 1.61$ \\
Total Lipid (mg / dL) & $259 \pm 45^{\mathrm{a}}$ & $193 \pm 31^{\mathrm{ab}}$ & $172 \pm 35^{\mathrm{b}}$ \\
Triacylglycerol (mg / dL) & $76 \pm 19^{\mathrm{a}}$ & $58 \pm 21^{\mathrm{ab}}$ & $28 \pm 14^{\mathrm{b}}$ \\
Phospholipid (mg / dL) & $120 \pm 11^{\mathrm{a}}$ & $101 \pm 7^{\mathrm{b}}$ & $93 \pm 8^{\mathrm{b}}$ \\
Non-esterified Fatty Acid ( $\mu$ Eq / L) & $435 \pm 104$ & $364 \pm 121$ & $275 \pm 40$ \\
Total Cholesterol (mg / dL) & $76 \pm 10^{\mathrm{a}}$ & $58 \pm 4^{\mathrm{b}}$ & $65 \pm 9^{\mathrm{ab}}$ \\
LDL-Cholesterol (mg / dL) & $7 \pm 1$ & $6 \pm 1$ & $5 \pm 1$ \\
HDL-Cholesterol (mg / dL) & $22 \pm 1^{\mathrm{a}}$ & $18 \pm 2 \mathrm{~b}$ & $19 \pm 1^{\mathrm{b}}$ \\
Total Ketone Body ( $\mu$ mol / L) & $1131 \pm 249$ & $923 \pm 398$ & $1068 \pm 374$ \\
Total Bile Acid ( $\mu$ mol / L) & $8 \pm 4$ & $5 \pm 3$ & $7 \pm 5$ \\
Insulin (ng / mL) & $0.946 \pm 0.547$ & $1.278 \pm 0.277$ & $0.843 \pm 0.458$ \\
\hline Triacylglycerol (mg / g-tissue) & $11.0 \pm 2.7^{\mathrm{a}}$ & $14.5 \pm 1.3^{\mathrm{ab}}$ & $18.6 \pm 3.1^{\mathrm{b}}$ \\
Total Cholesterol (mg / g-tissue) & $1.97 \pm 0.18^{\mathrm{a}}$ & $2.53 \pm 0.22^{\mathrm{ab}}$ & $2.81 \pm 0.56^{\mathrm{b}}$ \\
Total Bile Acid (nmol / g-tissue) & $13.8 \pm 1.7^{\mathrm{a}}$ & $17.4 \pm 3.4^{\mathrm{a}}$ & $25.6 \pm 2.3^{\mathrm{b}}$ \\
\hline Liver & & &
\end{tabular}

bshaded cell entries: significant difference detected by Tukey-Kramer comparison $(p<0.05)$

a,ab no significant difference compared with L-group

Hepatic TG, total cholesterol, and total bile acids were measured using Cholestest TG, Cholestest CHO (Sekisui Medical, Tokyo, Japan), and total bile acids assay kits (Diazyme Laboratories, Poway, CA, USA), respectively.

\section{DNA microarray assay}

Total RNA was isolated from each immersed hepatic piece, WAT, and BAT by TRIzol reagent (Invitrogen Japan, Tokyo, Japan) and purified using RNeasy mini kits (Qiagen). Anti-sense RNA was synthesized from 100 or $200 \mathrm{ng}$ of purified total RNA, and biotinylated complementary RNA (cRNA) was obtained using a GeneChip 3'IVT Express Kit (Affymetrix, Santa Clara, CA, USA). The cRNA was fragmented and hybridized to a GeneChip Rat Genome 230 2.0 Array (Affymetrix) for $16 \mathrm{~h}$ at $45{ }^{\circ} \mathrm{C}$. The arrays were washed and stained with phycoerythrin using the GeneChip Fluidics Station 450 (Affymetrix) and submitted to scanning on an Affymetrix GeneChip Scanner 3000 7G. The Affymetrix GeneChip Command Console Software was used to make CEL files.

\section{DNA microarray data analysis}

The CEL files derived from the liver, WAT, and BAT were quantified using robust multi-array average (RMA), factor analysis for robust microarray summarization (quantile normalization, qFARMS), and GCRMA, respectively $[19,22,46]$, using the statistical language $\mathrm{R}(2.7 .1)$ (http://www.r-project.org/) (R [35]), and Bioconductor (2.2) (http://www.bioconductor.org/) [15]. Hierarchical clustering was performed using the pvclust function in $\mathrm{R}$ [41]. The rank products (RP) method was used to identify differentially expressed gene probe sets of the quantified data [3]. The probe sets with a false discovery rate (FDR) $<0.05$ were considered to be differentially expressed between each group ( $\mathrm{L}$ vs $\mathrm{M}, \mathrm{M}$ vs $\mathrm{H}$, and $\mathrm{L}$ vs $\mathrm{H}$ ).

The up- and downregulated probe sets picked out at FDR $<0.05$ were functionally classified by the Biological Process in Gene Ontology (GO) with the Functional Annotation Tool of the Database for Annotation, Visualization, and Integrated Discovery (DAVID) $[9,21]$ and Quick GO (http://www.ebi.ac.uk/QuickGO/) [20]. In analysis of the liver, EASE scores, which are modified Fisher's exact test $p$ values were used to extract statistically overrepresented GO terms, and GO terms with $p$ values $<0.01$ were regarded as significantly enriched. In analysis of WAT and BAT, Benjamini-Hochberg correction $p$ values were used to extract statistically overrepresented GO terms, and GO terms with $p$ values $<0.05$ were regarded as significantly enriched. 
Predicted upstream regulators among liver and adipose tissue transcriptomes were analyzed using Qiagen's Ingenuity Pathway Analysis (IPA, Qiagen, https://www.qiagenbioinformatics.com/products/ingenuitypathway-analysis/). Activation $z$-scores were calculated as a measure of upstream regulators analysis. An absolute z-score $\geq 2.5$ was judged as significantly activated or inhibited. Common upstream regulators that were predicted to be activated or inhibited in the liver, WAT, and BAT were picked out from a list of all upstream regulators.

\section{Statistical analysis}

The results are shown as the means \pm SDs. One-way ANOVA was used to assess the differences among three groups, and Tukey-Kramer comparison was used for pairwise comparisons between multiple groups. Differences at $p \leq 0.05$ were considered to be significant.

\section{Results}

Characterization of hepatic genes affected by the altered balance of carbohydrate and fat in the diet

Rats were fed three kinds of diets containing different ratios of $\mathrm{C}-\mathrm{F}$ in constant total energy ( $\mathrm{L}, \mathrm{M}$, and $\mathrm{H}$, Additional file 1). In our preliminary experiment of feeding ad libitum, energy intakes (Kcal/g-BW) were almost the same among the three groups from week 2 to week 4 . Therefore, rats were pair-fed to keep by isoenergetic conditions, and dietary restriction derived from pairfeeding has not been occurred. During the experimental period of 9 weeks, the rats in each group showed no between-group differences in body weight (Additional file 2a, b). Also, the liver and the WAT weights showed no differences among groups (Additional file $2 \mathrm{~b})$. Biochemical analysis of the blood revealed differences in several markers among experimental groups (Table 1). The $\mathrm{H}$-group showed higher levels of alanine aminotransferase (ALT) and lower levels of TG, phospholipid, and HDL cholesterol (HDL-Chl). The M-group showed lower levels of phospholipids, total $\mathrm{Chl}$, and HDL-Chl. In addition, the liver biochemical analysis indicated increases in TG, total Chl, and total bile acid (BA) in the H-group. Serum insulin levels did not change among the three groups (Table 1 ).

The liver transcriptomes of the H-group were segregated from those in the L- and M-groups in the cluster dendrogram (Fig. 1). To dissect this overall difference in transcriptomes at a single gene level, we analyzed the coincidence of differentially expressed genes (DEGs) estimated from the comparison among $\mathrm{L}-, \mathrm{M}-$, and $\mathrm{H}-$ groups (Fig. 2a). The DEGs were termed according to the experimental groups and the number of members. For example, LM43 +83 formed the smallest population among MH131 + 106 and LH206 + 230, and shared about half of the members $(15+5$ and $40+1)$ with LH206 +230 .

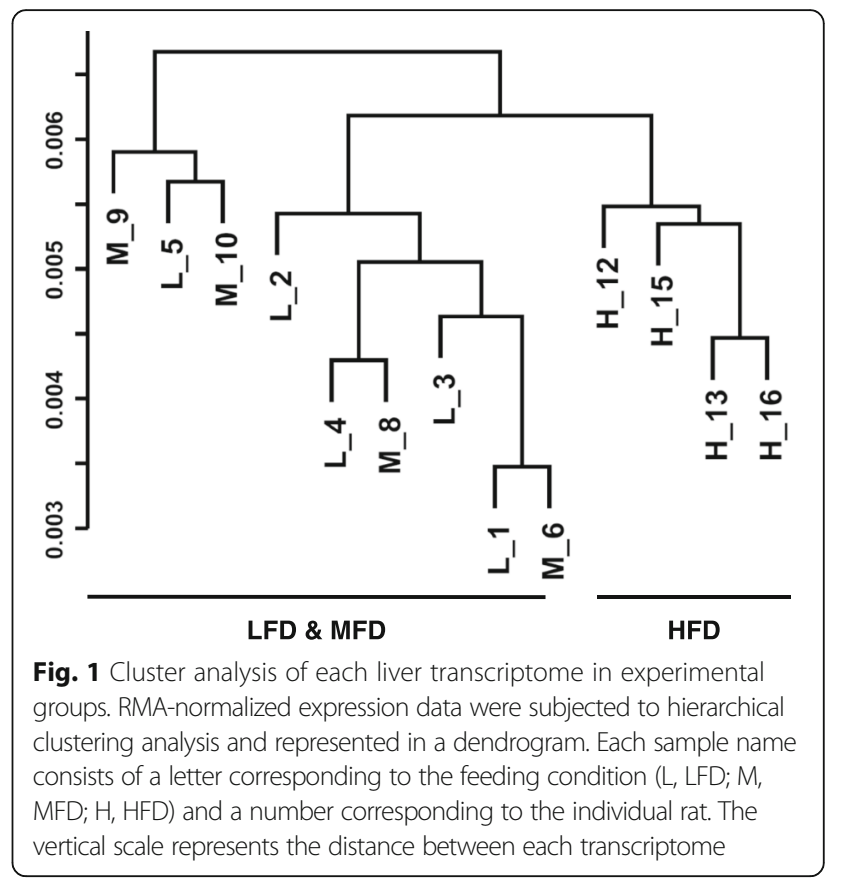

In contrast, about one third of LH206 +230 members were included by $\mathrm{MH} 131+106$. This indicates that the transcriptomic change from $\mathrm{L}$ to $\mathrm{H}$ is more similar to the change from $\mathrm{M}$ to $\mathrm{H}$ than the change from $\mathrm{L}$ to $\mathrm{M}$.

Then, we examined the function of the DEGs specific to the $\mathrm{L}$ vs $\mathrm{H}$ change $(\mathrm{LH} 186+189$ probe sets, Fig. 2a shaded area) using GO enrichment analysis [9, 21]. As a result, 53 genes were attributed to the nine GO terms located at the lowest position in the hierarchy (Table 2). Among these GO terms, four terms were related to lipid metabolism (GO0019216, 0006633, 0008203, and 0033189). The enriched genes included $5+3$ metabolic enzyme genes. Fads1, Msmo1, Cyp7b1, Idi1, and Sqle were upregulated and Cyp4a1, Elovl5, and Scd1 were downregulated in the H-group (Additional file 3, shaded cell entries), suggesting down- or upregulation of PUFA synthesis and upregulation of $\mathrm{Chl} / \mathrm{BA}$ synthesis. In addition, Apoa4, a key regulator of enteric and hepatic TG transportation was downregulated in the H-group. Other members of this category were mostly regulatory protein genes such as Prkaal (protein kinase, AMPactivated, alpha 1) and 2, Srebf1 (sterol regulatory element-binding transcription factor 1), Illa (interleukin-1 alpha), glucocorticoid receptor, Lepr (leptin receptor), and Dusp1 (MAPK phosphatase); among these, only Srebf1 was upregulated and the others were downregulated in the $\mathrm{H}$-group. There were 6 genes that belong to the GO term, circadian rhythm (GO0007623). Upregulation of Arntl/Clock, Npas2/Clock paralog, and Egfr (epidermal growth factor receptor) as day genes and downregulation of Prf1(perforin 1), Per (period circadian clock) 1 and 2 as night genes in the H-group was 

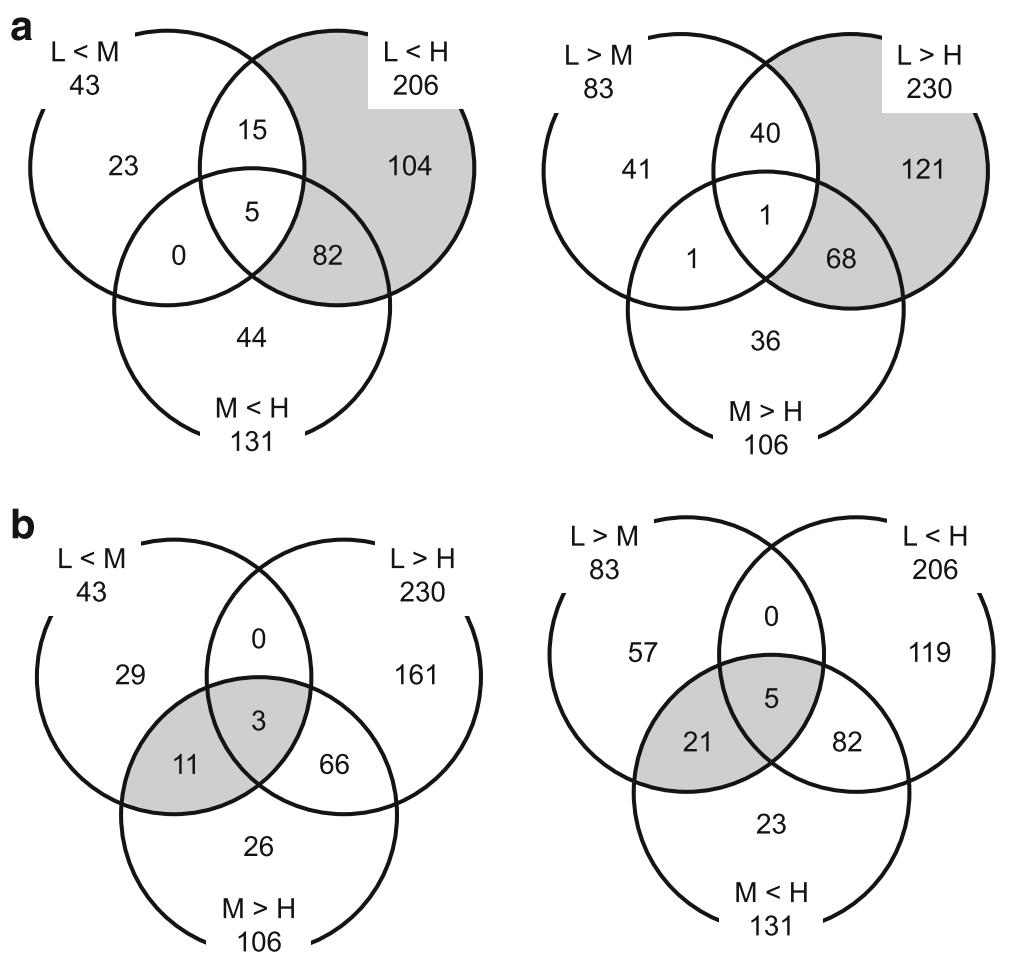

Fig. 2 Number of liver probe sets that were differentially expressed between experimental groups. a Coincidence of DEGs among experimental groups. The subsets of DEGs specific to the L vs $\mathrm{H}$ change are indicated by shaded areas. $\mathbf{b}$ Oppositely regulated DEGs (shaded areas)

consistent with the reversed expression pattern of these genes at the time point of tissue sampling (zeitgeber time 3) [2]. Fourteen genes were identified as those related to RNA polymerase II-dependent transcription (GO0045944 and 0000122); among these, only Ppargc1b $(P g c 1 b)$ was upregulated, and the others were downregulated in the H-group.

Besides the significant enrichment of $\mathrm{LH} 186+189$ genes to the GO terms related to lipid metabolism, $\mathrm{LM} 43+83$ genes were hard to analyze in this way because of the small population. We then dissected these genes with reference to the regulation of $\mathrm{M}$ vs $\mathrm{H}$ or L vs $\mathrm{H}$ DEGs (Fig. 2b). It was revealed that $14+26$ probe sets were reversely regulated compared with $\mathrm{L}$ vs $\mathrm{H}$ or $\mathrm{M}$ vs $\mathrm{H}$ DEGs (Table 3). These sets included 11 metabolic enzyme genes (shaded cell entries): $S d s$ (serine dehydratase) for utilization of glycogenic amino acids; Acot1 (acyl-CoA thioesterase 1) for negative regulation of beta-oxidation; Acsm2 (acyl-CoA synthetase mediumchain family member 2 ) for positive regulation of FA

Table 2 Significantly enriched GO terms found in liver LH186 + 189 genes

\begin{tabular}{|c|c|c|c|}
\hline GO-ID & Term & $p$ value & $\begin{array}{l}\text { Gene } \\
\text { count }\end{array}$ \\
\hline \multicolumn{4}{|c|}{ Biological process } \\
\hline 0007623 & Circadian rhythm & $1.82 \mathrm{E}-03$ & \\
\hline 0007568 & Aging & $5.77 \mathrm{E}-03$ & 10 \\
\hline 0009991 & Response to extracellular stimulus & $5.66 \mathrm{E}-04$ & 17 \\
\hline 0031667 & Response to nutrient levels & $2.20 \mathrm{E}-03$ & 15 \\
\hline 0033189 & Response to vitamin A & $4.30 \mathrm{E}-02$ & 9 \\
\hline 0016525 & Negative regulation of angiogenesis & $9.58 \mathrm{E}-03$ & 4 \\
\hline 0006882 & Cellular zinc ion homeostasis & $9.78 \mathrm{E}-03$ & 3 \\
\hline 0019216 & Regulation of lipid metabolic process & $4.72 \mathrm{E}-03$ & 9 \\
\hline 0016053 & Organic acid biosynthetic process & $3.59 \mathrm{E}-04$ & 12 \\
\hline 0046394 & Carboxylic acid biosynthetic process & $3.59 \mathrm{E}-04$ & 12 \\
\hline 0006633 & Fatty acid biosynthetic process & $4.39 \mathrm{E}-03$ & 7 \\
\hline 0006631 & Fatty acid metabolic process & $1.49 \mathrm{E}-04$ & 14 \\
\hline 0008610 & Lipid biosynthetic process & $9.86 \mathrm{E}-03$ & 13 \\
\hline 0008203 & Cholesterol metabolic process & $7.85 \mathrm{E}-04$ & 8 \\
\hline 0008202 & Steroid metabolic process & 7.11E-04 & 12 \\
\hline 0016125 & Sterol metabolic process & $2.15 \mathrm{E}-04$ & 9 \\
\hline 0051254 & Positive regulation of RNA metabolic process & $7.84 \mathrm{E}-03$ & 18 \\
\hline 0045893 & Positive regulation of transcription, DNA-dependent & 7.11E-03 & 18 \\
\hline 0045944 & Positive regulation of transcription from RNA polymerase II promoter & $7.29 \mathrm{E}-03$ & 16 \\
\hline
\end{tabular}

Shaded cell entries indicate GO terms at the lowest hierarchy 
Table 3 The list of the reversely regulated liver $L M 43+83$ genes

\begin{tabular}{|c|c|c|c|c|}
\hline \multicolumn{2}{|c|}{ Expression pattern } & Probe ID & Gene symbol & Description \\
\hline \multirow{14}{*}{$\begin{array}{c}14 \text { probe sets } \\
\mathrm{L}<\mathrm{M} \text { and } \mathrm{M}>\mathrm{H}\end{array}$} & & 1369268_at & Atf3 & activating transcription factor 3 \\
\hline & $\mathrm{L}>\mathrm{H}$ & 1370988_at & Сур2b1 & cytochrome P450, family 2 , subfamily b, polypeptide 1 \\
\hline & & 1393510_at & Golsyn & Golgi-localized protein \\
\hline & & 1382451_at & Hebp2 & heme binding protein 2 \\
\hline & & 1382284_at & LOC685440, Nek3 & similar to NIMA (never in mitosis gene a)-related expressed kinase 5, NIMA (never in mitosis gene a)-related kinase 3 \\
\hline & & 1397745_at & Mib1 & mindbomb homolog 1 \\
\hline & & 1369202_at & Mx2 & myxovirus (influenza virus) resistance 2 \\
\hline & $\mathrm{L}>\mathrm{H}$ & 1389990_at & RGD15637 & similar to Gene model 609 \\
\hline & & 1383956_at & RGD1565709 & similar to ovostatin- 2 \\
\hline & & 1397859_x_at & RT1-A3 & RT1 class I, locus A3 \\
\hline & $\mathrm{L}>\mathrm{H}$ & 1369864_a_at & Sds & serine dehydratase \\
\hline & & 1373740_at & --- & -- \\
\hline & & 1382517_at & --- & $-\cdots$ \\
\hline & & 1392860_at & --- & $-\ldots$ \\
\hline \multirow{23}{*}{$\begin{array}{c}26 \text { probe sets } \\
\mathrm{L}>\mathrm{M} \text { and } \mathrm{M}<\mathrm{H}\end{array}$} & $\mathrm{L}<\mathrm{H}$ & 1398250_at & Acot1 & acyl-CoA thioesterase 1 \\
\hline & & 1370436_at & Acsm2 & acyl-CoA synthetase medium-chain family member 2 \\
\hline & $\mathrm{L}<\mathrm{H}$ & 1374610_at & Agpat9 & 1-acylglycerol-3-phosphate O-acyltransferase 9. \\
\hline & & 1368121_at & Akr7a3 & aldo-keto reductase family 7 , member A3 (aflatoxin aldehyde reductase) \\
\hline & & 1383242_a_at & Cebpa & CCAAT/enhancer binding protein (C/EBP), alpha \\
\hline & & 1389625_at & Chchd4 & coiled-coil-helix-coiled-coil-helix domain containing 4 \\
\hline & & 1384392_at & Сур26b1 & cytochrome P450, family 26 , subfamily b, polypeptide 1 \\
\hline & & 1368607_at & Сур4a8 & cytochrome P450, family 4, subfamily a, polypeptide 8 \\
\hline & & 1388342_at & Etv3 & Ets variant 3 \\
\hline & & 1387670_at & Gpd2 & glycerol-3-phosphate dehydrogenase 2, mitochondrial \\
\hline & $\mathrm{L}<\mathrm{H}$ & 1371942_at & Gstt3 & glutathione S-transferase, theta 3 \\
\hline & & 1370912_at, 1368247_at & Hspala, Hspalb & heat shock $70 \mathrm{kD}$ protein $1 \mathrm{~A}$, heat shock $70 \mathrm{kD}$ protein $1 \mathrm{~B}$ (mapped) \\
\hline & & 1389251_at & Nudt7 & nudix (nucleoside diphosphate linked moiety X)-type motif 7 \\
\hline & & 1397164_at & Pola2 & polymerase (DNA directed), alpha 2 \\
\hline & & 1392854_at & RGD1564560 & Similar to RCK \\
\hline & & 1373777_at & Rgs16 & regulator of G-protein signaling 16 \\
\hline & $\mathrm{L}<\mathrm{H}$ & 1371143_at & Serpina7 & serine (or cysteine) peptidase inhibitor, clade A (alpha-1 antiproteinase, antitrypsin), member 7 \\
\hline & $\mathrm{L}<\mathrm{H}$ & 1389142_at & Sqrdl & sulfide quinone reductase-like (yeast) \\
\hline & & 1393160_at & Tbx3 & T-box 3 \\
\hline & & 1374924_at & Upf3b & UPF3 regulator of nonsense transcripts homolog B (yeast) (predicted) \\
\hline & & 1380306_at, 1381553_at, 1392613_at & Zbtb16 & zinc finger and BTB domain containing 16 \\
\hline & & 1393192_at & --- & 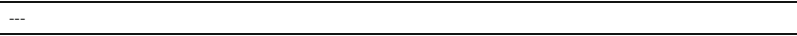 \\
\hline & & 1397225_at & --- & -.- \\
\hline
\end{tabular}

Shaded cell entries: metabolic enzyme genes related to lipid

synthesis; Agpat9 (1-acylglycerol-3-phosphate $O$-acyltransferase 9) for TG synthesis; Gpd2 (glycerol-3-phosphate dehydrogenase 2, mitochondrial) for gluconeogenesis from glycerol; and Cyp2b1, Akr7a3, Cyp26b1, Cyp4a8, Gstt3, and $S q r d l$ for detoxication. The other genes were involved in more diversified functions. This result indicates that the M-group is situated in a nutritional condition that controls the regulatory switching of these metabolic genes.

\section{Response of the adipose tissue transcriptomes to the increased ratio of fat to carbohydrate}

Because the hepatic transcriptome response as described above suggested some change in energetic interaction with other tissues such as adipose tissues, we analyzed the transcriptomes of WAT and BAT in each experimental condition (Table 4). The L vs H DEGs of these tissues were subjected to GO term enrichment analysis as in the case of the liver. WAT LH235 + 336 DEGs showed marked enrichment to the terms related to lipid metabolism (42 genes to GO0008610, 0006635, and 0045444)
(Table 5), and most of the metabolic enzyme genes were downregulated in the $\mathrm{H}$-group (Additional file 4). It is possible that both lipid synthesis and beta-oxidation were suppressed in this condition. Other characteristics of WAT LH235 + 336 DEGs were the high frequency of regulatory protein genes in the $\mathrm{GO}$ terms related to glucose metabolism (GO006006) (Pik3r1, Lep, Il6st, Igf2, Atf3, Crem, Pdk1, and Ppp1r1a, totally 8 genes/another 13 genes), and insulin signaling (GO0032868) (Lyn, Foxo1, Acvr1c, Pde3b, and Shc1, totally 5 genes/another 9 genes). Most of these genes were downregulated in the H-group except Lep encoding satiety hormone leptin,

Table 4 Differentially expressed genes in the liver and in the adipose tissues

\begin{tabular}{lll}
\hline Tissue & $\mathrm{L}<\mathrm{H}$ & $\mathrm{L}>\mathrm{H}$ \\
\hline Liver & 206 & 230 \\
WAT & 235 & 336 \\
BAT & 212 & 405 \\
\hline
\end{tabular}


Table 5 Significantly enriched GO terms found in WAT LH235 + 336 genes

\begin{tabular}{|c|c|c|c|}
\hline GO-ID & Term & $p$ value & Count \\
\hline \multicolumn{4}{|c|}{ Biological process } \\
\hline 0008610 & Lipid biosynthetic process & $6.17 \mathrm{E}-06$ & 25 \\
\hline 0045444 & Fat cell differentiation & $1.96 \mathrm{E}-04$ & 10 \\
\hline 0001503 & Ossification & 2.57E-04 & 13 \\
\hline 0060348 & - Bone development & 4.80E-05 & 15 \\
\hline 0005996 & Monosaccharide metabolic process & 4.41E-06 & 21 \\
\hline 0019318 & Hexose metabolic process & $8.08 \mathrm{E}-06$ & 19 \\
\hline 0006006 & Glucose metabolic process & 1.18E-05 & 17 \\
\hline 0009991 & Response to extracellular stimulus & $1.43 \mathrm{E}-06$ & 28 \\
\hline 0031667 & Response to nutrient levels & $1.20 \mathrm{E}-05$ & 25 \\
\hline 0007584 & :-... Response to nutrient & 2.84E-04 & 18 \\
\hline 0009719 & -.-.-Response to endogenous stimulus & $1.89 \mathrm{E}-08$ & 47 \\
\hline 0009725 & Response to hormone & $1.25 \mathrm{E}-07$ & 42 \\
\hline 0043434 & Response to peptide hormone & $1.59 \mathrm{E}-04$ & 20 \\
\hline 0032868 & . Response to insulin & 4.31E-04 & 14 \\
\hline 0010033 & Response to organic substance & 4.50E-09 & 65 \\
\hline 0016042 & Lipid catabolic process & $3.15 \mathrm{E}-04$ & 14 \\
\hline 0044242 & Cellular lipid catabolic process & $1.33 \mathrm{E}-04$ & 11 \\
\hline 0009062 & Fatty acid catabolic process & $2.42 \mathrm{E}-05$ & 9 \\
\hline 0006635 & Fatty acid beta-oxidation & $2.70 \mathrm{E}-05$ & 8 \\
\hline 0046395 & Carboxylic acid catabolic process & $1.17 \mathrm{E}-05$ & 14 \\
\hline 0016054 & Organic acid catabolic process & $1.17 \mathrm{E}-05$ & 14 \\
\hline 0006631 & Fatty acid metabolic process & 3.43E-08 & 24 \\
\hline 0019395 & Fatty acid oxidation & $3.85 \mathrm{E}-04$ & 8 \\
\hline 0034440 & Lipid oxidation & $3.85 \mathrm{E}-04$ & 8 \\
\hline 0055114 & Oxidation-reduction process & $1.62 \mathrm{E}-04$ & 34 \\
\hline
\end{tabular}

Shaded cell entries indicate GO terms at the lowest hierarchy

Il6st encoding IL-6 inflammatory signal transducer, and Lyn encoding tyrosine kinase. There were 12 genes attributed to the GO terms related to bone formation (GO0060348 and GO0001503).

BAT LH212 + 405 DEGs exhibited a regulatory pattern similar to that of WAT DEGs (Table 6), where all of the enzyme genes related to lipid metabolism were downregulated in the H-group (24 genes in GO0006631 and 0006695, shaded cell entries in Additional file 5). The other 23 enzyme genes were in the oxidation-reduction category (GO0055114) of which 15 genes were downregulated in the H-group. BAT DEGs also contained another 46 genes classified as organic substance responsive components (GO0010033) that encode regulatory proteins, transcription factors (SREBF2, glucagon receptor), and transporters. The remainder was 12 genes for muscle contraction (GO0006936) such as actin, myosin, and troponin genes.

\section{Search for upstream regulators common among the liver and adipose tissues}

Given the results of GO analysis that the H-diet generally induced the upregulation of FA unsaturation and Chl synthesis in the liver (Additional file 3) and the downregulation of FA synthesis in the adipose tissues
(Additional files 4 and 5), we assessed whether these gene regulations were caused by some biological signals common among these tissues using the Ingenuity Pathway Analysis (IPA). Table 7 lists the IPA upstream regulators that were predicted to be activated or repressed (absolute $\mathrm{z}$-score $>2.5$ ) from the input of L vs $\mathrm{H}$ DEGs (Table 4). Relatively high $z$-scores were observed with LY294002 (PI3 kinase inhibitor) in WAT (3.07) and BAT (2.73) [44], suggesting the inhibition of insulin signaling in the H-group. This is consistent with the result that two well-known components of insulin downstream signaling (SREBF1 for FA synthesis and SREBF2 for Chl synthesis) were inactivated (negative $z$-scores) both in WAT ( -3.68 and -4.18$)$ and BAT ( -3.52 and -4.17$)$. It is also notable that INSIG (insulin-induced gene protein) 1 and 2, which play roles as repressors of SREBF [48, 49], seemed to be activated in BAT (3.61 and 2.93). In addition, pirinixic acid, a specific agonist of PPAR (peroxisome proliferator-activated receptor) alpha, was detected as a WAT/BAT common upstream regulator. The negative $z$-scores for pirinixic acid $(-3.07$ in WAT and -2.99 in BAT) suggest the repression of this process. The liver transcriptome showed relatively low absolute $z$-scores except for peptidylprolyl isomerase F (PPIF or cyclophilin D) $(z$-score $=2.83)$. 
Table 6 Significantly enriched GO terms found in BAT LH212 + 405 genes

\begin{tabular}{|c|c|c|c|}
\hline GO-ID & Term & $p$ value & Count \\
\hline \multicolumn{4}{|c|}{ Biological process } \\
\hline 0055114 & Oxidation-reduction process & $4.18 \mathrm{E}-06$ & 41 \\
\hline 0010033 & Response to organic substance & $6.50 \mathrm{E}-06$ & 61 \\
\hline 0006631 & Fatty acid metabolic process & 4.40E-05 & 20 \\
\hline 0003012 & --. Muscle system process & $1.43 \mathrm{E}-05$ & 15 \\
\hline 0006936 & Muscle contraction & $8.02 \mathrm{E}-05$ & 13 \\
\hline 0008610 & -.-. Lipid biosynthetic process & $2.59 \mathrm{E}-11$ & 36 \\
\hline 0006694 & Steroid biosynthetic process & $6.54 \mathrm{E}-05$ & 12 \\
\hline 0016126 & Sterol biosynthetic procell & $4.38 \mathrm{E}-08$ & 11 \\
\hline 0006695 & Cholesterol biosynthetic process & 7.52E-09 & 11 \\
\hline 0008203 & Cholesterol metabolic process & $3.75 \mathrm{E}-08$ & 16 \\
\hline 0016125 & Sterol metabolic process & $1.01 \mathrm{E}-07$ & 16 \\
\hline 0008202 & --Steroid metabolic process & $7.84 \mathrm{E}-06$ & 20 \\
\hline
\end{tabular}

Shaded cell entries indicate GO terms at the lowest hierarchy

\section{Discussion}

We have analyzed the transcriptomic responses of the liver and adipose tissues to an increased ratio of $\mathrm{F}$ to $\mathrm{C}$ under isoenergetic conditions. In this study, three types of diets were adjusted with soybean oil to construct the $\mathrm{C}$-F ratios, since it is the major oil in human diets. Soybean oil has some beneficial effects $[45,50]$, and hepatic transcriptomes can be influenced by oil and fat profiles [18]. Although the fatty acid profile was different among three diets because of identical quantities of lard rich in saturated FA, it is crucial that the main energy resource was changed from $C$ to $F$. The rats showed no betweengroup differences in body weight or in relative tissue weight (Additional file 2b); however, higher serum ALT levels were observed in the $\mathrm{H}$-group compared with the $\mathrm{L}$ - and M-groups (Table 1). Because no significant fluctuations were observed among the other damage markers, the liver damage in the H-group seems to be limited in extent. This is in accordance with the fact that no significant enrichment of DEGs detected in GO terms related to liver damage, such as inflammation or fibrosis [25].

Interestingly, $\mathrm{H}$-group rats exhibited a significant biochemical characteristic relevant to lipid homeostasis: lower TG and HDL-Chl levels in the sera and higher TG, total Chl, and total BA content in the liver than in

Table 7 Comparison of IPA upstream regulators among the liver and the adipose tissue transcriptomes

\begin{tabular}{|c|c|c|c|c|}
\hline \multicolumn{2}{|r|}{ Upstream Regulator } & \multicolumn{3}{|c|}{ Activation z-score } \\
\hline Abbreviation & Description & Liver & WAT & BAT \\
\hline LY294002 & PI3 kinase inhibitor & -0.756 & 3.07 & 2.73 \\
\hline SREBF1 & Sterol regulatory element-binding transcription factor 1 & 1.27 & -3.68 & -4.18 \\
\hline SREBF2 & Sterol regulatory element-binding transcription factor 2 & 1.12 & -3.52 & -4.17 \\
\hline INSIG1 & Insulin induced gene 1 & -2.15 & 1.61 & 3.61 \\
\hline INSIG2 & insulin induced gene 2 & - & 2.39 & 2.93 \\
\hline PPARG & peroxisome proliferator-activated receptor (PPAR) gamma & -1.01 & -2.73 & -2.15 \\
\hline gemfibrozil & PPAR alpha activator & -1.57 & -2.21 & -2.80 \\
\hline pirinixic acid & PPAR alpha activator & -1.79 & -3.07 & -2.99 \\
\hline CREB 1 & cAMP responsive element binding protein 1 & 0.751 & -3.17 & -2.14 \\
\hline IL4 & interleukin 4 & 0.789 & -2.64 & -2.41 \\
\hline MLXIPL & $\begin{array}{l}\text { MLX interacting protein-like, Carbohydrate-responsive } \\
\text { element-binding protein }\end{array}$ & - & -2.41 & -2.61 \\
\hline CD38 & CD38 molecule & -0.269 & -2.28 & -3.41 \\
\hline paclitaxel & taxol & 1.19 & -2.19 & -2.66 \\
\hline PPIF & peptidylprolyl isomerase F, cyclophilin D & 2.83 & 0.200 & 2.00 \\
\hline
\end{tabular}

The absolute Z-scores of larger than 2.5 are represented by the shaded cell entries. -; no significant Z-score Upstream Regulators are classified according to their relevance to each other 
the L-group (Table 1). Our transcriptomic analysis suggested the upregulation of Chl/BA synthesis in the liver (Table 2 and Additional file 3), the downregulation of lipid synthesis and beta-oxidation in WAT (Table 5 and Additional file 4), and the downregulation of Chl biosynthesis in BAT (Table 6 and Additional file 5). The former liver transcriptomic response may facilitate acetyl-CoA consumption via Chl synthesis and BA secretion (Fig. 3) [43]. Moreover, the downregulation of Scd1 and Elovl5 indicates suppression of de novo synthesis and elongation of monounsaturated FAs, while the upregulation of Fads1 implies facilitation of C20 PUFAs (precursors of bioactive eicosanoids) synthesis from 18:2 n-6 linoleic acid, rich in H-diet, with the help of Fads2 [24]. These results suggest that the hepatic transcriptome was regulated not only by the C-F ratios but also by the fatty acid profiles of the diets. The downregulation of Apoa4 may inhibit export of TG from the liver leading to the decrease in serum TG level and the increase in liver TG content (Fig. 3) [42]. The latter responses of adipose tissues may suppress FA release to the sera.

A comparison of $\mathrm{L}$ vs $\mathrm{M}$ transcriptomes in liver showed $126(43+83)$ genes as differentially expressed (Fig. 2); this was less than the number of differentially expressed genes as compared to $M$ vs $H(131+106$ genes) and $\mathrm{L}$ vs $\mathrm{H}(206+230$ genes). This means that the transcriptome of the L-group was more closely related to that of the M-group than $\mathrm{H}$-group (Fig. 1). Then, we analyzed LM43 + 83 DEGs to clarify C-F ratio dependency of hepatic transcriptome and we found 32 reversely regulated genes (i.e., upregulated in $\mathrm{M}$ condition and downregulated in $\mathrm{H}$-condition, or vice versa) (listed in Table 3). These reversely regulated liver DEGs can exert potential effects on lipid homeostasis; the upregulation of Acot1, Acsm2, and Agpat9 in the $\mathrm{H}$-group may increase TG accumulation in the liver. Also, the role of LM43 + 83 DEGs in macronutrient conversion (e.g., amino acid to $\mathrm{C}$ and $\mathrm{F}$ to $\mathrm{C}$ ) should be emphasized because our study was conducted under the isoenergetic conditions. In this context, the downregulation of $S d s$ in the H-group may reduce utilization of amino acids for gluconeogenesis, and the upregulation of $G p d 2$ in the H-group may increase gluconeogenesis from glycerol produced by TG hydrolysis. Because the expression pattern of these genes was biphasic, the regulation of these metabolisms may have a balancing point close to the M-condition. As we used outbred Wistar rats, transcriptomic difference among the L-group and the M-group could be influenced by genetic or epigenetic differences between animals. Further indirect calorimetric studies with altered C-F ratios or animal strains are needed to clarify this metabolic regulation switching.

A question arising is whether these transcriptomic regulations are governed by any cellular signals common among these tissues. We computationally detected the downregulation of both insulin-PI3K-SREBF and PPAR alpha signals in the adipose tissues but not in the liver (Table 7). This suggests that both the anabolic signal of insulin (i.e., FA synthesis) and the catabolic signal of PPAR alpha (i.e., FA oxidation) are inhibited in adipose tissues. Because the rats in the H-group showed a growth rate (Additional file $2 \mathrm{~b}$ ) and serum insulin levels almost the same as in the L- and M-groups (Table 1), the suppression of insulin signals may be intrinsic to

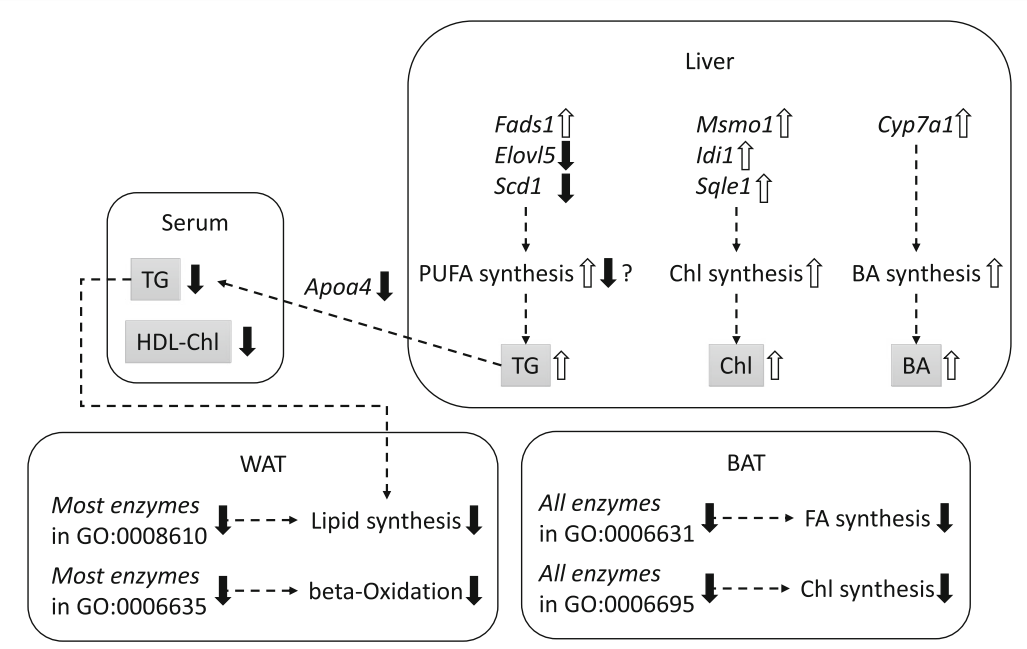

Fig. 3 Transcriptomic and metabolic changes in H-condition compared to L-condition. Shaded molecules indicate the metabolites, and others indicate the transcripts specific to L vs H change (liver LH186 + 189, WAT LH235 + 336, and BAT LH212 + 405). Upward arrows indicate the H-up genes (italics) or predicted pathways compared to L-condition, and vice versa. TG triacylglycerol, Chl cholesterol, BA bile acid, FA fatty acid, PUFA polyunsaturated fatty acid 
adipose tissues [33, 40, 47]. In the case of PPAR alpha signal, the low level of serum TG in the H-group might affect the concentration of FA in adipose tissues.

\section{Conclusions}

To investigate the effects of altered dietary C-F ratio, we compared with L vs M and L vs H DEGs. We found that hepatic genes for gluconeogenesis and lipid metabolism were reversely regulated, indicating that a turning point for gene expression switching from $\mathrm{C}$ to $\mathrm{F}$ as energy source may exist in the $\mathrm{M}$-condition $(\mathrm{C}: \mathrm{F}=60: 20)$ or a $\mathrm{C}-\mathrm{F}$ ratio around $\mathrm{M}$.

$\mathrm{L}$ vs $\mathrm{H}$ analyses revealed that high-fat diet upregulated Chl/BA synthesis in the liver and downregulated lipid synthesis in WAT and BAT. Also, our computational search for upstream regulators in these tissues suggested that insulin and PPAR alpha signals were downregulated both in WAT and BAT in the H-group.

In conclusion, the liver and adipose tissues differentially adapts to altered $\mathrm{C}$-F by changing their gene expressions and not by merely responding to endocrine signals.

\section{Additional files}

Additional file 1: Composition of diets. (DOCX $17 \mathrm{~kb}$ )

Additional file 2: Physical parameters of the animals. a, Energy intake during the experimental period. The intakes of the rats in the $\mathrm{M}$ - and $\mathrm{H}$-groups were restricted to the average intake of the rats in the L-group. Data for the $\mathrm{M}$ - and $\mathrm{H}$-groups after day 0 were omitted. b, Body and tissue weights. The inset represents the relative tissue weights (percent to body weight) at the time of sacrifice (week 9). Values are represented as means \pm SD $(n=4-5)$. (DOCX $89 \mathrm{~kb})$

Additional file 3: The list of liver $\mathrm{LH} 186+189$ genes that belongs to the GO terms located at the lowest level of hierarchy. (DOC $143 \mathrm{~kb}$ )

Additional file 4: The list of WAT $\mathrm{LH} 235+336$ genes that belong to the GO terms located at the lowest level of hierarchy. (DOC $190 \mathrm{~kb}$ )

Additional file 5: The list of BAT $\mathrm{LH} 212+405$ genes that belong to the $\mathrm{GO}$ terms located at the lowest level of hierarchy. (DOC $213 \mathrm{~kb}$ )

\section{Abbreviations}

\section{Experimental conditions}

C: Carbohydrate; F: Fat; P: Protein; LFD or L: Low-fat diet; MFD or

M: Moderate-fat diet; HFD or H: High-fat diet

Methods and biochemical terms

ALT: Alanine aminotransferase; BA: Bile acid; BAT: Brown adipose tissues; Chl: Cholesterol; DEGs: Differentially expressed genes; FA: Fatty acid; FDR: False discovery rate; GO: Gene ontology; HDL: High-density lipoprotein; INSIG: Insulin-induced gene protein; IPA: Ingenuity Pathway Analysis; PPAR: Peroxisome proliferator-activated receptor; PPIF: Peptidylprolyl isomerase F (cyclophilin D); PUFA: Polyunsaturated fatty acid; SREBF: Sterol regulatory element-binding transcription factor; TG: Triacylglycerol; WAT: White adipose tissues

Genes

Acot1: Acyl-CoA thioesterase 1; Acsm2: Acyl-CoA synthetase medium-chain family member 2; Acvr1c: Activin A receptor, type IC; Agpat9: 1-Acylglycerol3-phosphate O-acyltransferase 9; Akr7a3: Aldo-keto reductase family 7, member A3 (aflatoxin aldehyde reductase); Apoa4: Apolipoprotein A-IV; Arntl/ Clock: Aryl hydrocarbon receptor nuclear translocator-like; Atf3: Activating transcription factor 3; Crem: CAMP responsive element modulator;

Cyp: Cytochrome P450; Dusp1: Dual specificity phosphatase 1; Egfr: Epidermal growth factor receptor; Elov15: ELOVL fatty acid elongase 5; Fads1: Fatty acid desaturase 1; Foxo 1: Forkhead box O1A; Gpd2: Glycerol-3-phosphate dehydrogenase 2, mitochondrial; Gstt3: Glutathione S-transferase, theta 3; Idi1: Isopentenyl-diphosphate delta isomerase 1; Igf2: Insulin-like growth factor 2; II a: Interleukin 1 alpha; I/6st: Interleukin 6 signal transducer; Lep: Leptin; Lepr: Leptin receptor; Lyn: LYN proto-oncogene, Src family tyrosine kinase; Msmo 1: Methylsterol monooxygenase 1; Npas2: Neuronal PAS domain protein 2; Pde3b: Phosphodiesterase 3B, cGMP-inhibited;

Pdk1: Pyruvate dehydrogenase kinase, isozyme 1; Per: Period circadian clock; Pik3r1: Phosphoinositide-3-kinase; Ppargc1b/Pgc1b: Peroxisome proliferatoractivated receptor gamma coactivator 1 beta; Ppp 1r1a: Protein phosphatase 1, regulatory (inhibitor) subunit 1A; Prf1: Perforin 1 (pore-forming protein); Prkaa: Protein kinase, AMP-activated, alpha; Scd1: Stearoyl-coenzyme A desaturase 1; Sds: Serine dehydratase; Shc1: SHC (Src homology 2 domain containing) transforming protein 1; Srebf1: Sterol regulatory element-binding transcription factor 1; Sqle: Squalene epoxidase; Sqrdl: Sulfide quinone reductase-like

\section{Acknowledgements}

The authors thank the Cross-ministerial Strategic Innovation Promotion Program (SIP) (Grant No. 14532924) in Japan for their support.

\section{Funding}

This research was supported by the Cross-ministerial Strategic Innovation Promotion Program (SIP) (Grant No. 14532924) in Japan. The funders had no role in the study design, data collection and analysis, decision to publish, or preparation of the manuscript.

\section{Availability of data and materials}

All DNA microarray data (CEL files) presented in this publication have been deposited in the National Center of Biotechnology Information (NCBI) Gene Expression Omnibus (http://www.ncbi.nlm.nih.gov/geo/) and are accessible through the accession number GSE79867.

\section{Authors' contributions}

The experimental design was constructed and supervised by MT and TN. The animal experiments and biochemical analysis were performed by MS, KK, and YS. MT, YS, and TA worked on the DNA microarray assay. The manuscript was drafted and written by AY, TN, and MT. All authors read and approved the final manuscript.

\section{Competing interests}

The authors declare that they have no conflict of interests.

\section{Consent for publication}

All authors have agreed to its publication in Genes and Nutrition.

\section{Ethics approval}

All animal experimental protocols were approved by the Animal Use Committee of the Takasaki University of Health and Welfare. All institutional and national guidelines for the care and use of laboratory animals were followed.

\section{Publisher's Note}

Springer Nature remains neutral with regard to jurisdictional claims in published maps and institutional affiliations.

\section{Author details}

${ }^{1}$ Nissin Global Innovation Center, Nissin Foods Holdings, 2100 Tobukimachi, Hachioji-shi, Tokyo 192-0001, Japan. ${ }^{2}$ Project on Health and Anti-Aging, Kanagawa Academy of Science and Technology, Life Science and Environment Research Center (LiSE) 4F C-4, 3-25-13 Tonomachi, Kawasaki-ku, Kawasaki, Kanagawa 210-0821, Japan. ${ }^{3}$ Department of Health and Nutrition, Takasaki University of Health and Welfare, 37-1 Nakaorui-machi, Takasaki, Gunma 370-0033, Japan. ${ }^{4}$ Department of Applied Biological Chemistry, Graduate School of Agricultural and Life Sciences, The University of Tokyo, 1-1-1 Yayoi, Bunkyo-ku, Tokyo 113-8657, Japan. 
Received: 22 June 2016 Accepted: 1 March 2017 Published online: 08 April 2017

\section{References}

1. Aguila MB, Pinheiro Ada R, Parente LB, Mandarim-de-Lacerda CA. Dietary effect of different high-fat diet on rat liver stereology. Liver Int. 2003;23:363-70.

2. Bell-Pedersen D, Cassone VM, Earnest DJ, Golden SS, Hardin PE, Thomas TL, Zoran MJ. Circadian rhythms from multiple oscillators: lessons from diverse organisms. Nat Rev Genet. 2005;6:544-56. doi:10.1038/nrg1633.

3. Breitling R, Armengaud P, Amtmann A, Herzyk P. Rank products: a simple, yet powerful, new method to detect differentially regulated genes in replicated microarray experiments. FEBS Lett. 2004;573:83-92. doi:10.1016/j. febslet.2004.07.055.

4. Cahill Jr GF. Starvation in man. Clin Endocrinol Metab. 1976;5:397-415.

5. Carter BA, Taylor OA, Prendergast DR, Zimmerman TL, Von Furstenberg R, Moore DD, Karpen SJ. Stigmasterol, a soy lipid-derived phytosterol, is an antagonist of the bile acid nuclear receptor. FXR Pediatr Res. 2007;62:301-6. doi:10.1203/PDR.0b013e3181256492.

6. Chai JW, Lim SL, Kanthimathi MS, Kuppusamy UR. Gene regulation in betasitosterol-mediated stimulation of adipogenesis, glucose uptake, and lipid mobilization in rat primary adipocytes. Genes Nutr. 2011;6:181-8. doi:10.1007/s12263-010-0196-4.

7. Coyle EF. Substrate utilization during exercise in active people. Am J Clin Nutr. 1995;61:968s-79s

8. Crescenzo R, Bianco F, Mazzoli A, et al. Fat quality influences the obesogenic effect of high fat diets. Nutrients. 2015;7:9475-91. doi:10.3390/ nu7115480.

9. Dennis Jr G, Sherman BT, Hosack DA, Yang J, Gao W, Lane HC, Lempicki RA. DAVID: Database for Annotation, Visualization, and Integrated Discovery. Genome Biol. 2003:4:3.

10. Deol P, Evans JR, Dhahbi J, Chellappa K, Han DS, Spindler S, Sladek FM. Soybean oil is more obesogenic and diabetogenic than coconut oil and fructose in mouse: potential role for the liver. PLoS One. 2015;10:e0132672. doi:10.1371/journal.pone.0132672

11. Duivenvoorde LP, van Schothorst EM, Swarts HM, Kuda O, Steenbergh E, Termeulen S, Kopecky J, Keijer J. A difference in fatty acid composition of isocaloric high-fat diets alters metabolic flexibility in male C57BL/6JOlaHsd Mice. PLoS One. 2015;10:e0128515. doi:10.1371/journal.pone.0128515.

12. Enns JE, Hanke D, Park A, Zahradka P, Taylor CG. Diets high in monounsaturated and polyunsaturated fatty acids decrease fatty acid synthase protein levels in adipose tissue but do not alter other markers of adipose function and inflammation in diet-induced obese rats. Prostaglandins Leukot Essent Fatty Acids. 2014;90:77-84. doi:10.1016/j.plefa. 2013.12.002.

13. Even PC, Bertin E, Gangnerau MN, Roseau S, Tome D, Portha B. Energy restriction with protein restriction increases basal metabolism and mealinduced thermogenesis in rats. Am J Physiol Regul Integr Comp Physiol. 2003;284:R751-759. doi:10.1152/ajpregu.00268.2002.

14. Folch J, Lees M, Sloane Stanley GH. A simple method for the isolation and purification of total lipides from animal tissues. J Biol Chem. 1957;226:497-509.

15. Gentleman RC, Carey VJ, Bates DM, et al. Bioconductor: open software development for computational biology and bioinformatics. Genome Biol. 2004:5:R80. doi:10.1186/gb-2004-5-10-r80.

16. Grattan Jr BJ. Plant sterols as anticancer nutrients: evidence for their role in breast cancer. Nutrients. 2013:5:359-87. doi:10.3390/nu5020359.

17. Hanke D, Zahradka P, Mohankumar SK, Clark JL, Taylor CG. A diet high in alpha-linolenic acid and monounsaturated fatty acids attenuates hepatic steatosis and alters hepatic phospholipid fatty acid profile in diet-induced obese rats. Prostaglandins Leukot Essent Fatty Acids. 2013;89:391-401. doi:10.1016/j.plefa.2013.09.009.

18. Hashimoto $Y$, Yamada K, Tsushima H, et al. Three dissimilar high fat diets differentially regulate lipid and glucose metabolism in obesity-resistant SIC: Wistar/ST rats. Lipids. 2013;48:803-15. doi:10.1007/s11745-013-3805-3.

19. Hochreiter S, Clevert DA, Obermayer K. A new summarization method for Affymetrix probe level data. Bioinformatics. 2006;22:943-9. doi:10.1093/ bioinformatics/btl033.

20. Hosack DA, Dennis Jr G, Sherman BT, Lane HC, Lempicki RA. Identifying biological themes within lists of genes with EASE. Genome Biol. 2003:4:R70. doi:10.1186/gb-2003-4-10-r70
21. Huang da W, Sherman BT, Zheng X, Yang J, Imamichi T, Stephens R, Lempicki RA. Extracting biological meaning from large gene lists with DAVID. Curr Protoc Bioinformatics. 2009;Chapter 13(Unit 13):11. doi:10.1002/ 0471250953.bi1311s27.

22. Irizarry RA, Hobbs B, Collin F, Beazer-Barclay YD, Antonellis KJ, Scherf U, Speed TP. Exploration, normalization, and summaries of high density oligonucleotide array probe level data. Biostatistics. 2003;4:249-64. doi:10. 1093/biostatistics/4.2.249.

23. Itoh H, Kaneko M, Ohshima S, Shumiya S, Sakaguchi E. Effect of low protein and low energy diet on physiological status and digestibility of F344 rats. Exp Anim. 2002:51:485-91.

24. Jump DB. Fatty acid regulation of hepatic lipid metabolism. Curr Opin Clin Nutr Metab Care. 2011:14:115-20. doi:10.1097/MCO.0b013e328342991c.

25. Kamei A, Watanabe Y, Shinozaki F, Yasuoka A, Kondo T, Ishijima T, Toyoda T, Arai $\mathrm{S}$, Abe K. Administration of a maple syrup extract to mitigate their hepatic inflammation induced by a high-fat diet: a transcriptome analysis. Biosci Biotechnol Biochem. 2015;79:1893-7. doi:10.1080/09168451.2015.1042833.

26. Kuda O, Jelenik T, Jilkova Z, et al. n-3 fatty acids and rosiglitazone improve insulin sensitivity through additive stimulatory effects on muscle glycogen synthesis in mice fed a high-fat diet. Diabetologia. 2009;52:941-51. doi:10.1007/s00125-009-1305-z.

27. Laos S, Caimari A, Crescenti A, Lakkis J, Puiggros F, Arola L, del Bas JM. Long-term intake of soyabean phytosterols lowers serum TAG and NEFA concentrations, increases bile acid synthesis and protects against fatty liver development in dyslipidaemic hamsters. Br J Nutr. 2014;112:663-73. doi:10. 1017/s0007114514001342.

28. Lien EL, Boyle FG, Wrenn JM, Perry RW, Thompson CA, Borzelleca JF. Comparison of AIN-76A and AIN-93G diets: a 13-week study in rats. Food Chem Toxicol. 2001;39:385-92.

29. Minana-Solis Mdel C, Escobar C. Post-weaning protein malnutrition in the rat produces short and long term metabolic impairment, in contrast to earlier and later periods. Int J Biol Sci. 2008:4:422-32.

30. Nyima T, Müller M, Hooiveld GJ, Morine MJ, Scotti M. Nonlinear transcriptomic response to dietary fat intake in the small intestine of C57BL/ 6J mice. BMC Genomics. 2016;17:106. doi:10.1186/s12864-016-2424-9.

31. Pavlisova J, Bardova K, Stankova B, Tvrzicka E, Kopecky J, Rossmeisl M. Corn oil versus lard: metabolic effects of omega-3 fatty acids in mice fed obesogenic diets with different fatty acid composition. Biochimie. 2016;124:150-62. doi:10.1016/j.biochi.2015.07.001.

32. Pimentel GD, Dornellas AP, Rosa JC, et al. High-fat diets rich in soy or fish oil distinctly alter hypothalamic insulin signaling in rats. J Nutr Biochem. 2012;23:822-8. doi:10.1016/j.jnutbio.2011.04.006.

33. Poletto AC, Anhê GF, Eichler $P$, et al. Soybean and sunflower oil-induced insulin resistance correlates with impaired GLUT4 protein expression and translocation specifically in white adipose tissue. Cell Biochem Funct. 2010; 28:114-21. doi:10.1002/cbf.1628.

34. Portillo MP, Chavarri M, Duran D, Rodriguez VM, Macarulla MT. Differential effects of diets that provide different lipid sources on hepatic lipogenic activities in rats under ad libitum or restricted feeding. Nutrition. 2001;17:467-73.

35. R Development Core Team. R: a language and environment for statistical computing. Vienna: R Foundation for Statistical Computing; 2006.

36. Racette SB, Spearie CA, Phillips KM, Lin X, Ma L, Ostlund Jr RE. Phytosteroldeficient and high-phytosterol diets developed for controlled feeding studies. J Am Diet Assoc. 2009;109:2043-51. doi:10.1016/j.jada.2009.09.009.

37. Renaud HJ, Cui JY, Lu H, Klaassen CD. Effect of diet on expression of genes involved in lipid metabolism, oxidative stress, and inflammation in mouse liver-insights into mechanisms of hepatic steatosis. PLoS One. 2014:9:e88584. doi:10.1371/journal.pone.0088584.

38. Romijn JA, Coyle EF, Sidossis LS, Gastaldelli A, Horowitz JF, Endert E, Wolfe RR. Regulation of endogenous fat and carbohydrate metabolism in relation to exercise intensity and duration. Am J Physiol. 1993;265:E380-391.

39. Shahkhalili Y, Mace K, Moulin J, Zbinden I, Acheson KJ. The fat:carbohydrate energy ratio of the weaning diet programs later susceptibility to obesity in male sprague dawley rats. J Nutr. 2011;141:81-6. doi:10.3945/jn.110.126557.

40. Shankar K, Harrell A, Kang P, Singhal R, Ronis MJ, Badger TM. Carbohydrateresponsive gene expression in the adipose tissue of rats. Endocrinology. 2010;151:153-64. doi:10.1210/en.2009-0840.

41. Suzuki R, Shimodaira H. Pvclust: an R package for assessing the uncertainty in hierarchical clustering. Bioinformatics. 2006:22:1540-2. doi:10.1093/ bioinformatics/btl117. 
42. VerHague MA, Cheng D, Weinberg RB, Shelness GS. Apolipoprotein A-IV expression in mouse liver enhances triglyceride secretion and reduces hepatic lipid content by promoting very low density lipoprotein particle expansion. Arterioscler Thromb Vasc Biol. 2013;33:2501-8. doi:10.1161/ atvbaha.113.301948.

43. Vidon C, Boucher P, Cachefo A, Peroni O, Diraison F, Beylot M. Effects of isoenergetic high-carbohydrate compared with high-fat diets on human cholesterol synthesis and expression of key regulatory genes of cholesterol metabolism. Am J Clin Nutr. 2001;73:878-84.

44. Vlahos CJ, Matter WF, Hui KY, Brown RF. A specific inhibitor of phosphatidylinositol 3-kinase, 2-(4-morpholinyl)-8-phenyl-4H-1-benzopyran4-one (LY294002). J Biol Chem. 1994;269:5241-8.

45. Wang $X$, Cheng $M$, Zhao $M$, et al. Differential effects of high-fat-diet rich in lard oil or soybean oil on osteopontin expression and inflammation of adipose tissue in diet-induced obese rats. Eur J Nutr. 2013;52:1181-9. doi:10.1007/s00394-012-0428-z.

46. Wu Z, Irizarry RA, Gentleman R, Martinez-Murillo F, Spencer F. A modelbased background adjustment for oligonucleotide expression arrays. J Am Stat Assoc. 2004;99:909-17. doi:10.1198/016214504000000683.

47. Xue B, Nie J, Wang X, DuBois DC, Jusko WJ, Almon RR. Effects of high fat feeding on adipose tissue gene expression in diabetic goto-kakizaki rats. Gene Regul Syst Bio. 2015;9:15-26. doi:10.4137/grsb.s25172.

48. Yabe D, Brown MS, Goldstein JL. Insig-2, a second endoplasmic reticulum protein that binds SCAP and blocks export of sterol regulatory elementbinding proteins. Proc Natl Acad Sci U S A. 2002;99:12753-8. doi:10.1073/ pnas.162488899.

49. Yang T, Espenshade PJ, Wright ME, et al. Crucial step in cholesterol homeostasis: sterols promote binding of SCAP to INSIG-1, a membrane protein that facilitates retention of SREBPs in ER. Cell. 2002;110:489-500.

50. Zhao $M$, Zang $B$, Cheng $M, M a$ Y, Yang $Y$, Yang N. Differential responses of hepatic endoplasmic reticulum stress and inflammation in diet-induced obese rats with high-fat diet rich in lard oil or soybean oil. PLoS One. 2013; 8:e78620. doi:10.1371/journal.pone.0078620.

\section{Submit your next manuscript to BioMed Central and we will help you at every step:}

- We accept pre-submission inquiries

- Our selector tool helps you to find the most relevant journal

- We provide round the clock customer support

- Convenient online submission

- Thorough peer review

- Inclusion in PubMed and all major indexing services

- Maximum visibility for your research

Submit your manuscript at www.biomedcentral.com/submit

) Biomed Central 